\title{
Too old to teach? Experiences of online teaching among FCS instructors aged 50 years old and up
}

\author{
Balce, Sarah E. $\triangle$ \\ Emilio Aguinaldo College, Philippines (balce.sarah@yahoo.com)

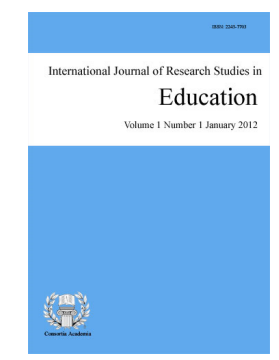

Accepted: 15 July 2021

ISSN: 2243-7703 Online ISSN: 2243-7711

OPEN ACCESS

\section{Abstract}

The global Coronavirus pandemic has since affected educational systems. Teachers as the facilitators of learning had to immediately learn how to navigate through online systems. Various adjustments were done in the institutional up to the individual instructor level. As with the common notion, such technological shift is a burden to the old-aged educators in here defined as those who are 50 years old and up. The present study sought to validate this claim by seeing through the lens of these instructors. Specifically, the study looked into the experiences of the teachers, their perceived performance, and actions and recommendations. Using the Social Constructivism theory and qualitative data gathering and analytical tools, five educators from Faith Christian School (FCS) were interviewed. Findings suggested that though the study participants were forced to adapt, they still found that an online setup is more convenient and enjoyable. Moreover, it was analyzed from the teachers' narratives that motivation and mindset are two aspects that still affect a teachers' dedication to learn and continue. As to their perceived performance, emerging themes included doubting about the teachers' technological capacity especially when resources are lacking. Towards the end of the study, a list of recommendations was provided.

Keywords: internal stakeholders; external stakeholders; education quality; private health institutes; health profession 


\section{Too old to teach? Experiences of online teaching among FCS instructors aged 50 years old and up}

\section{Introduction}

The Pandemic has shifted perspectives, operations, and lives in a fast, unexpected way. Services, industries, and even government services had to shift in automated transactions where everyone was forced to maximize connection in a cloud, moving around using only a device and an internet connection. In the education world, physical classes immediately shifted to online classes pushing school staff, educators, and students to adjust in an online set-up. This grave shift brought discussions and reconsiderations in various education mindsets. According to the Director of Organisation for Economic Co-operation and Development (OECD) in an online meeting held in October 2020, the pandemic has further emphasized inequalities in the education system including the "failure to attract talented teachers to the most challenging classrooms" (Schleicher, 2020).

Among the major individuals gravely affected with the technological shift in education are teachers who had to relearn and quickly adjust. In a study conducted by Zhao et al. (2020), it was found that teachers at first believed that positive attitudes have a positive influence on a student's academic performance. However, they also believed that the higher the grade of the students, the more it would decrease their interest in actual "learning." Consequently, Purwanto et al. (2020) found out that among selected teachers qualitatively interviewed, the following emerged as benefits of work-from-home arrangement: (1) Flexibility in work completion - in various areas inside the house in whatever comfortable look and position; (2) Flexible working hours; (3) Saved money and time that could otherwise be spent in travel; (4) Work and personal duties and responsibilities may be done without compromising either, and; (5) The teachers themselves may create their preferred atmosphere. In contrast, the study also enumerated the disadvantages quantitatively collected: (1) Work mood and motivation may easily be lost; (2) Higher cost in electricity and internet, and; (3) Overly technology-dependent connection and communication with other instructor/school staff colleagues.

\subsection{The technological shift}

The idea of an online teaching set-up is not entirely new. Conferences, discourse, and other informative and consultative events were already done in the past to spread the awareness of the potential of a fully online education system (Niemi \& Kousa, 2020). However, the reality is that once the system goes online, it should be carried along with empowered and knowledgeable users from both the teachers and the students. Though there were debates before that online classrooms do not level a physical setup, there remains gaps in terms of further understanding this shift. Baran, Correia, and Thompson (2011) mentioned that online learning would not become too facilitative for students unless the old, traditional ways of teachers will also change. Moreover, the study stated that though the concept of online learning would get as much attention now, there is still lack of research about teachers' roles and competencies in an online setup.

\subsection{The new normal teachers}

Unlike the common notion, teachers are not totally negative when distance education including online classroom setup is taken into account. In fact, Niemi and Kousa (2020) stated that teachers are more concerned with how they would prepare and train themselves in the transition. The challenge is for them to make students feel that though the setup is not physical, they are not isolated. These instructors believe that in order to achieve this, the whole institution has to move as one. Niemi and Kousa (2020), in their qualitative study, found the following categories when they asked the perceptions of teaching during the pandemic. Emerging themes included: (1) Interaction with students; (2) Evaluation of learning; (3) Workload of teachers and students; (4) Students' motivation, and; (5) Technology. In an exploratory study conducted by Baran et al. (2013), teachers felt 
the struggle in making themselves visible and heard during online classrooms. Their teacher personas, affected by their past and present roles and experiences, depend on various factors. According to the said study, one of the crucial aspects to attain a successful online teaching is having a support mechanism.

One factor that was seen relevant with regards to teacher's approaches in an online setup is age (Badia, Garcia, $\&$ Meneses, 2015). Interestingly, the study found that the older the online teachers are, the more likely they will adopt various approaches online. In terms of teachers' readiness in online teaching, Scherer, Howard, Tondeur, and Siddiq (2021) argued that individual and contextual perspectives must be considered as their readiness is beyond only their self-efficacy and teaching presence. Another study conducted by Lapada, Robledo, Miguel, and Alam (2020) found that Filipino teachers are mentally prepared to shift in an online setup if they have institutional support. However, the teachers feel "hampered" because of the lack of school equipment, facilities, and resources to assist them in the shift. They then had to adjust their interventions which had to be different from their face-to-face encounters.

\subsection{Theoretical framework: Social constructivism}

Social Constructivism is based on the assumption that reality is crafted by social interaction. It is not discovered, rather it is constructed socially and culturally. Interaction is a core aspect of this theory as it emphasizes that individuals create meanings from the environment and the people around them (Kim, 2006). Learning, using a social constructivist approach, is considered as a "learning process." External forces are working towards creating a learning atmosphere for an individual. Therefore, in Social Constructivism, personal meanings may be found in a person's experiences and interaction with the environment (Kim, 2006). Intersubjectivity is another aspect of Social Constructivism. Not only does an individual's personal meanings are influenced by external factors, but the individual himself or herself also influences these factors (Kim, 2006). By the social constructivism theory, the general objective of this study was an inquiry about how the teachers who are the "facilitators of learning" become the ones who needed to "learn" and adapt with the new normal teaching.

\subsection{Research Questions}

In line with the abovementioned researches, the present study sought to understand how did FCS instructors aged 50 years above cope with the technological shift brought about by the pandemic in the school setting. Specifically, the research wanted to explore:

$>\quad$ What are the experiences of the teachers aged 50 years old above with regards to the technological shift in the instructional setting brought about by the pandemic? Challenges? and Coping Mechanisms?

$>$ How did the technological shift affect the teachers' perceptions on their performance?

$>\quad$ What actions or recommendations can be done to assist the teachers during an immediate shift in educational setting based on their experiences?

\subsection{Scope and Limitations}

The present study is limited to only selected instructors in the Faith Christian School. Since the study participants are unique, they were purposively selected to serve the interests of the study. Data gathering was done through Zoom as the pandemic and changing quarantine status prohibited the researcher to conduct a physical meetup. The data analysis, on the other hand, was done using the lens of Social Constructivism. In addition, the present study did not aim to generalize a certain population but sought to explore a phenomenon that has not yet been experienced by specific individuals. Only five (5) school instructors were interviewed for this study. In a qualitative enquiry, such numbers are acceptable once the data saturation point is reached (Fusch \& Ness, 2015). 


\section{Methodology}

\subsection{Research Design}

As the study is exploratory in nature, it was designed to be qualitative research. In this type of analysis, the following aspects are recognized (Anderson, 2010):

$>\quad$ Research framework and direction are flexible depending in new emerging data;

$>\quad$ Context is crucial as a macro perspective to understand a phenomenon used. With this, details and complexities of data are acknowledged which are often disregarded by quantitative analysis;

$>\quad$ Interviews are not close-ended and may vary depending on the researcher's encounter with the study participants;

Furthermore, in qualitative analysis, data are collected from very few individuals unlike positivistic approaches as the aim is not to generalize to a certain population. However, findings may also be applicable to the same contexts or settings. Such analysis is used to understand an individual's beliefs, experiences, values, interactions and the like. It does not depend on any numerical or statistical data but the actual voices of its participants (Pathak, Jena, \& Kalra, 2013).

\subsection{Sampling and Research Participants}

Purposive sampling was used in the present study. This sampling is a non-probability type which is the most commonly used sampling technique. As such, data generated from the study may not be generalized to a certain population (Acharya, Prakash, Saxena, \& Nigam, 2013).

As the phenomenon is exclusive to certain age groups and experiences, only five (5) participants matched the following criteria:

1. An instructor / teacher currently employed in Faith Christian School for more than three (3) years;

2. Age has to be 50 years old and above;

3. Usage of online software for teaching must be at least 3 days a week, and;

4. Is available during the schedule of the interview.

The research participants' demographic characteristics were taken first before the actual data were analyzed. In total, five (5) teachers consented. Table 1 enumerates the basic information of the participants. Their names were not mentioned here to keep their privacy.

\section{Table 1}

Basic information of the participants

\begin{tabular}{ccccc}
\hline Identification Code & Age & Gender & $\begin{array}{c}\text { No. of Years } \\
\text { teaching at FCS }\end{array}$ & $\begin{array}{c}\text { Utilization rate of online } \\
\text { software } \\
\text { (No. of days a week) }\end{array}$ \\
\hline A1 & 52 & Female & 12 & 7 days \\
A2 & 55 & Male & 4 & 7 days \\
A3 & 58 & Male & 7 & 3 days \\
A4 & 52 & Female & 28 & 3 days \\
A5 & 52 & Female & 30 & 5 days \\
\hline
\end{tabular}

14 Consortia Academia Publishing (A partner of Network of Professional Researchers and Educators) 


\subsection{Sampling and Research Participants}

Before the actual interviews with the participants, the researcher familiarized herself with the Social Constructivism theory which will be used in the actual analysis. Using the semi-structured interview guide crafted, the researcher also thought of possible probing questions that may be discussed during the actual interview. Guidelines as to how to conduct a qualitative interview were also reviewed so as to ensure that all necessary data will be gathered.

During the start of the online interview, consent forms were explained among the research participants. The researcher also sought their signatures from the forms provided. The interview was done via Zoom as it is the most convenient platform among the participants and the researcher. The whole interview was recorded for analysis. Each interview lasted for an average of 30 minutes to a maximum of an hour. According to Adams (2015), an hour is an acceptable duration of semi-structured interviews.

In terms of analysis, the recorded videos were transcribed first. Afterwards, the transcribed data were familiarized and tagged with labels easily identifiable to the researcher. These labels already became the preliminary codes which were then categorized and reviewed again. Such codes were redefined and were filtered again to check what codes may already be merged into major themes. Lastly, emerging themes were described and validated with present and relevant literature. The overall qualitative analysis process was guided by Gibson's (2013) guide to qualitative data analysis.

\section{Results and Discussion}

This section discusses the research findings of the present study. The discussion here is ordered according to the research questions as follows: (1) What are the experiences of the teachers aged 50 years old above with regards to the technological shift in the instructional setting brought about by the pandemic - Challenges and Coping Mechanisms?; (2) How did the technological shift affect the teachers' perceptions on their performance?, and; (3) What actions or recommendations can be done to assist the teachers during immediate shift in educational setting based on their experiences?

Table 2

Final Thematic Map

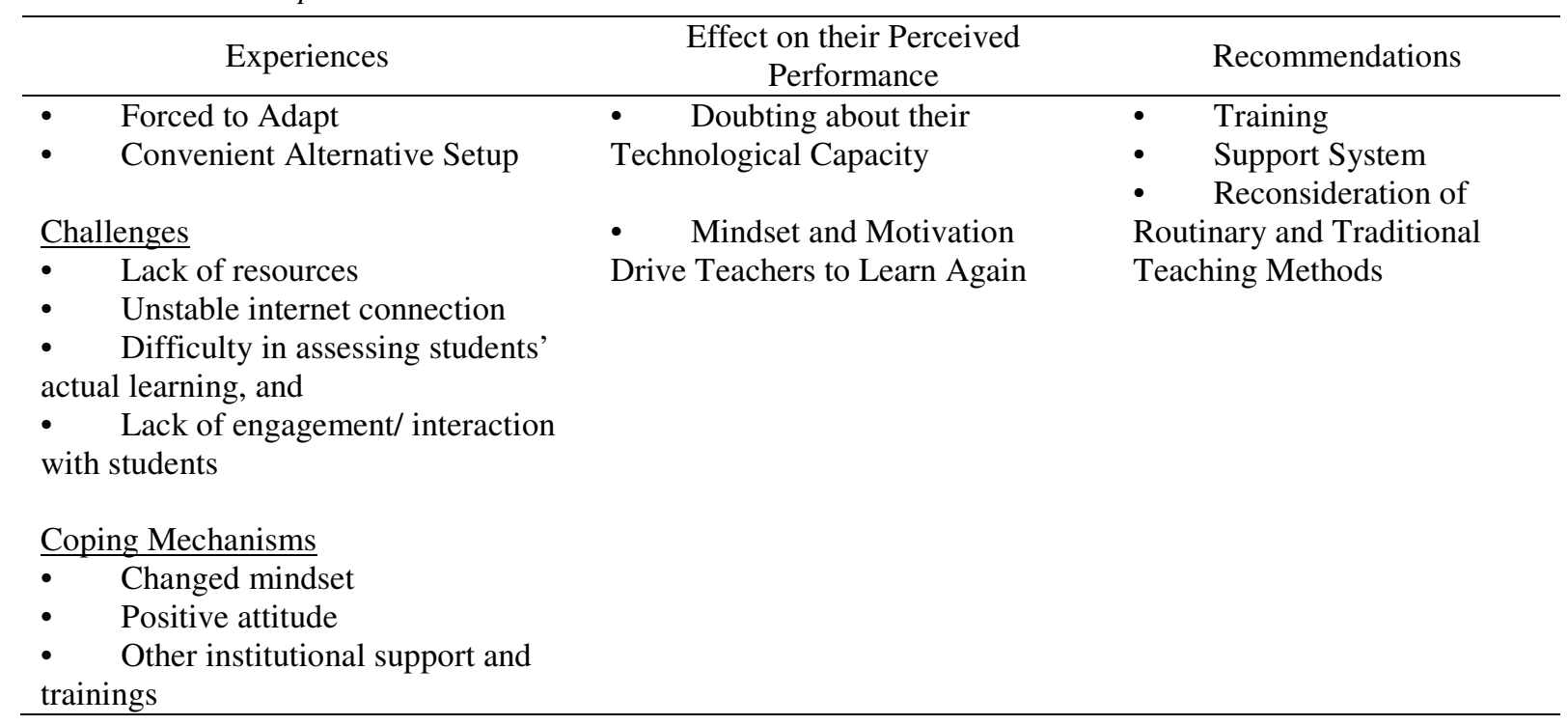




\subsection{Experiences of the Selected FCS Teachers}

Two emerging themes were noted from the narratives of the study participants regarding their experiences during the shift of teaching setup: The transition made them worry, but they had to force themselves to adapt, and the online setup was a convenient and enjoyable alternative after all.

Forced to Adapt - During the time when the Philippine government announced that face-to-face classes were prohibited, online learning systems became a go. The study participants admitted that this brought fear and worry among them as they were "old enough" to change their teaching routines and strategies.

"That was the first time that I really felt the fear of how am I going to prepare my lessons if I do not even know how to edit? I know how to prepare powerpoint presentations but the powerpoint presentations that I usually see during discussions and whenever I have time to be with my other co-teachers and look at their presentations and listen and see how they present it, I think that 'will I ever make that kind of presentation?' That was the fear at first because I am not tech-savvy." -A1

"When President Duterte announced that there will be a lockdown and there will be no more face to face schooling or we are not allowed to go to school, I had the fear. Definitely, there will be online classes and computer and I really had a hard time. That is the reality... we will be online." -A4

Adding to the teachers' fears is the limitations and challenges they encountered along the way: Lack of resources, unstable internet connection, difficulty in assessing students' actual learning, and lack of engagement/interaction with students.

“...We actually do not have desktop computer, so you will be left behind. So I was forced to load to be able to have a desktop." -A5

"The thing that cannot be controlled is the connection. That is the problem. I actually have times where I rattle. I struggle if I am lagging, especially when my pupils are commenting like,

“Teacher, you are freezing or you are lagging..." -A4

"Lastly, the weight of teaching. I find it difficult especially in terms of the skill they need because it is easier to teach theory than actual practice because of my subject. Theory is easy to teach but skills are difficult to teach online because I can't afford to show them the hearing output or the actual task." -A2

"Then, you should be aware if students receive or not. You just don't lead the class, you should feel the reception of the students if they understand or not. Actually, that instinct. It's up to the teacher. However, communication should be intact. You will go back to your function as a teacher. You should feel that students understand your instructions.”-A3

"Since we are talking about preschoolers, their fine motors are not yet developed. One of the goals of a preschool teacher is to help them and guide their hands on how to hold the pencil, how to hold it properly and correctly. How to color the proper way-up and down, up and down. So you really need to demonstrate, you have to hold his hand on how to do these things. So how can you do that online?" -A5

Niemi and Kousa (2020) also found the same challenges as how teachers perceived the shift during the pandemic - interaction with students, evaluation of learning, and technology. Lapada et al. (2020) also confirmed that the lack of school equipment, facilities, and resources made the shift more difficult.

To cope up with these challenges, the participants mentioned that they had to change their mindset and keep

16 Consortia Academia Publishing (A partner of Network of Professional Researchers and Educators) 
Too old to teach? Experiences of online teaching among FCS instructors aged 50 years old and up

a positive attitude. In addition, a support system and training were proven to help the teachers cope up easier and faster.

"So I have a fear that I will not be able to present my powerpoint as beautiful as others do like that Ma'am. But eventually, I was wrong. Because I was able to grasp it and it was actually a challenge for me. So no! This is the new normal so I have to have a mindset that I can do it so each time I attend a seminar, I have a small notebook and then I write everything there-how to enter Zoom, how to share screen, how to make test in Edmodo, how to upload files, things like that Ma'am. So put it all in that little notebook."-A1

“Sir *** monitors us. But when I worry, I ask my kids to teach me.”-A3

“Yes. Just because I'm older. But it's different now, I ask them to mentor me.”-A4

In terms of coping mechanisms, Joshi, Bhaskar, and Vinay (2020) mentioned that besides the teachers' lack of technical know-how, a teacher's negative attitude and lack of motivation affect their online teaching and evaluation.

Convenient and Enjoyable Alternative Setup - The teachers agreed that transitioning to an online setup is not overly disadvantageous. Instead, most of them agree that online setup is actually convenient in their daily lives. Though learning cannot be compared in a face-to-face arrangement, there are also pros in it.

"Of course you're in your home. It is easier to manage your students because you are just sitting down. You will just look at the screen to monitor them. I like online setup better.”-A3

"There is a big difference. In school, you spend 6 hours with the kids while in online class, you actually spend less time." -A4

"The happiness is incomparable in face-to-face classes but I actually enjoyed online class. I learned to enjoy it because before I always had a husky voice in face to face classes and this year, I was able to maintain my voice so I really enjoy it and then of course, Maam, I was able to do my lesson virtually and really enjoyed it. The first time I did it, I had so much worry but along the way, I enjoyed it because I thought of the learnings I will have. I learned so much about using the computer so along the way, I really enjoyed it." -A1

The positive experiences and positive reflections of teachers coincide with the qualitative data found by Niemi and Kousa (2020). Though the pandemic resulted in a totally different setup, teachers still show their motivation in teaching.

\subsection{Effects on the Perceived Performance}

The narratives of the study participants highlight their perceptions among themselves before the pandemic and how they adjusted with such. Emphasizing their mindset and motivation, they were able to realize that they can indeed learn new ways to teach their students.

Doubting about their Technological Capacity - All the teachers agreed that the shift from face-to-face teaching to an online classroom was difficult. They had to relearn and start from nowhere in order to adapt with the new normal teaching. Interestingly, all the teachers viewed themselves as "slow to learn and adapt to technology, and not at all 'tech-savvy.'" This came from the fact that the instructors already acknowledge their old age. This is how they perceived themselves and their performance during the transition.

"The 1st quarter. I think, those been a couple of weeks since we transitioned. Those times, I

totally don't have any knowledge about technology, it's really slow." -A3 
"I am not techy, Ma'am. That is the top 1. I started our last school that the only thing I know is to search for pictures and copy and paste. That is mostly what I know, copy and paste."-A5

"At first it was a bit difficult because, of course, as I have mentioned earlier when I was faced last year with the thought of going online, the first thing that really worries me is I am not really teach-savvy."-A1

Moreover, the study participants agreed that they are used to traditional methods which made it more difficult for them to adjust in the new normal.

"I am used to compute grades or any activity like making my visual aids and everything using a paper and a pen, a permanent pen. I preferred to use paper and class records. Though computers were already introduced before, I still preferred to use class records that time because it would be difficult to teach me. So I preferred to use pen and paper." -A4

Wilichowski and Cobo (2020) agreed that teachers are having a hard time coping up with the new educational arrangement. They also argued that as teachers generally want to deliver effective instructions, they are limited by their technological capacity and appropriate skills. Decoito and Richardson (2018) also affirmed that knowledgeable teachers are a must to meet educational goals.

Mindset and Motivation Drive Teachers to Learn Again - Two particular scenarios were observed from the narratives of the study participants-A1 was challenged but was positively motivated to learn the online setup, while A4 admitted thinking of filing a resignation already.

"I was able to do my lesson virtually and really enjoyed it. The first time I did it, I had so much worry but along the way, I enjoyed it because I thought of the learnings I will have. I learned so much about using the computer so along the way, I really enjoyed it." -A1

A1 was even recognized and was the one encouraging others to cope up and continue to learn.

"Yes. I would just encourage them not to give up because just like this, when we are overwhelmed, we don't want to learn it anymore. It is actually a challenge even if we are in this age. I am 53, I am happy, I am still learning and I can still be at par with other young teachers."-A1

A4, teary-eyed during the interview, admitted that she thought of filing resignation, and sought advice from her husband.

"Step by step, nakacope up ako sa difficulty. I admitted, Maam, before, I really want to resign. I really want to cry, Maam... I also asked permissed from my husband, I told him, I want to quit because I cannot adapt. But he told me, "You can do it!". You don't know that Ma'am but I will actually resign back then." -A4

At the end of the day, it all goes back to the teachers' mindset and motivation in doing their jobs.

"We really wanted to give the best to our students but when we are talking about the time, it is actually not enough to teach children in the time given to us." -A4

"It becomes even more challenging for me if I look at the negative side, I might be depressed. But the good thing about being a child of God, you may go through difficult times, you have a God to lean on and will help you to look at the better side. Although it is difficult, you bear it." -A5

Of the many factors analyzed by Sorebo, Halvari, Gulli, and Kristiansen (2009), they found out that perceived e-learning competence actually influences their pre-acceptance expectations. The study further

18 Consortia Academia Publishing (A partner of Network of Professional Researchers and Educators) 
Too old to teach? Experiences of online teaching among FCS instructors aged 50 years old and up

discussed that realistic pre-expectations will bring efficient technology.

\title{
3.3 Recommendations
}

Based on the teachers' experiences, they recommended the following that could be done forward-looking:

\section{Transition has to be controlled and in a gradual state}

"So, can we cope up? Think, transition should be gradual. Transitioning to online, the students, teachers, facilities, and everything, I think, the transition should be gradual. If the students will transition to face-to-face, they need assistance so it should be gradual. For teachers to go back to face-to-face, for instance, two or three years in online class, they might find it hard to adjust in the classroom. So, I think, the transition should be gradual.”-A2

A2 emphasized that in order to come up with a controlled atmosphere, the transition should be gradual.

\section{Continuous training and provision of constant technical and mental support must be given.}

\begin{abstract}
"Okay. I am willing. Just what I said, if there would be training, especially about technology, I would attend. At least, I will have an advantage and I can catch up." -A3

"Actually with all honesty, I learned a lot from our training before, however, experience is really an edge and when somebody is beside you teaching you technically. Experience and when someone is teaching you. When someone is beside you and teaching you that helps me a lot." -A5
\end{abstract}

Niemi and Kousa (2020) also agreed that with training, teachers learned to utilize technology or connection problems as they can already solve them quickly. Institutional support is also a must as the shift is not a teacher level concern, but the whole of the educational institution (Lapada et al., 2020). Moreover, government policies must also be taken into consideration here (Yurcaba, 2020). Furthermore, the educational system must build this support among its teachers (Wilichowski \& Cobo, 2020). Specifically, policies should be increased for teachers' capacity building, opportunities should be maximized to develop their innovative teaching skills, and plans to support the said skill. Following up regularly of the status of the teachers could also help.

\section{Reconsideration of Routinary and Traditional Teaching Methods could be done.}

To answer the lack of assessment or evaluation tool to gauge a student's output or performance, reconsideration of the grading system and rubrics could be done. This was actually a recommendation as well by teachers as documented in the study of Niemi and Kousa (2020). To appropriately support teachers as they cope through this crisis, it is crucial that remote learning plans acknowledge the unique constraints of home-based learning (Wilichowski \& Cobo, 2020). Moreover, DeCoito and Richardson (2018) stated that to achieve improvements in teacher technology use, certain activities must be done and evaluated to target teachers themselves.

\section{Conclusions}

The pandemic indeed challenged the educational system to explore alternatives from the traditional classroom type teaching. Educators were forced to adapt with their own strategies and some with older ages were tapping into the dark side. Nevertheless, this season has taught lessons to the institutional system, educators, teachers, and school staff.

In contrast with the common notion that old teachers would become too negative and slowly adapt with the immediate technological shift in the educational system brought about by the pandemic, this exploratory study proved that mindset and motivation are two factors that still affect a teachers' dedication to learn and continue. 
Related studies and literature considered in the present study also highlight the fact that teachers in different contexts have almost the same struggles which cut across resources, skills, attitudes, and limited connectivity. Interestingly, they are mostly concerned on how they can effectively teach their students and how their students react and provide feedback to their teaching.

This paper explored perspectives and actual experiences of teachers aged fifty years old and up with regards to the immediate shift in the technology because of the pandemic. Lessons and recommendations from this research may be used as inputs to improve school policies and strategies to maintain teaching effectiveness of instructors with different technical capabilities and age.

\section{References:}

Acharya, A., Prakash, A., Saxena, P., \& Nigam, A. (2013). Sampling: Why and how of it? Indian Journal of Medical Specialties, 2(4), 330-333. https://doi.org/10.7713/ijms.2013.0032

Adams, W. (2015). Conducting semi-structured interviews. In the Handbook of practical program evaluation (4th ed., pp. 492-505). https://doi.org/10.1002/9781119171386.ch19

Anderson, C. (2010). Presenting and evaluating qualitative research. American Journal of Pharmaceutical Education, 74(8), 141. https://doi.org/10.5688/aj7408141

Badia, A., Garcia, C., \& Meneses, J. (2017). Approaches to teaching online: Exploring factors influencing teachers in a fully online university. British Journal of Educational Technology, 48(6), 152-189. https://doi.org/10.1111/bjet.12475

Baran, E., Correia, A., \& Thompson, A. (2011). Transforming online teaching practice: Critical analysis of the literature on the roles and competencies of online teachers. Distance Education journal, 32(2), 421-439. https://doi.org/10.1080/01587919.2011.610293

Baran, E., Correia, A., \& Thompson, A. (2013). Tracing successful online teaching in higher education: Voices of exemplary online teachers. Teachers College Record, 115, 1-41.

Fusch, P., \& Ness, L. (2015). Are we there yet? Data saturation in qualitative research. Qualitative Report, 20(9), 1408-1416. https://doi.org/10.46743/2160-3715/2015.2281

Gibson, N. (2003). A step-by-step guide to qualitative data analysis. Retrieved from https://www.researchgate.net/publication/292432218_A_Step-By-Step_Guide_To_Qualitative_Data_A nalysis/link/59a34e40a6fdcc1a315f5978/download

Joshi, A., Bhaskar, P., \& Vinay, M. (2020). Impact of coronavirus pandemic on the Indian education sector: Perspectives of teachers on online teaching and assessments. Article in Interactive Technology and Smart Education. https://doi.org/10.1108/ITSE-06-2020-0087

Kim, B. (2006). Social Constructivism: From emerging perspectives of learning, teaching, and technology. The University of Georgia.

Lapada, A., Robledo, D., Miguel, F., \& Alam, Z. (2020). Teachers' COVID-19 awareness, distance learning education experiences and perceptions towards institutional readiness and challenges. International Journal of Learning, Teaching, and Educational Research, 19(6), 127-144. https://doi.org/10.26803/ijlter.19.6.8

Niemi, H. M., \& Kousa, P. (2020). A case study of students' and teachers' perceptions in a Finnish high school during the COVID pandemic. International Journal of Technology in Education and Science, 4(4), 352-369. https://doi.org/10.46328/ijtes.v4i4.167

Pathak, V., Jena, B., \& Kalra, S. (2013). Qualitative research. Perspectives in Clinical Research, 4(3), 192. https://doi.org/10.4103/2229-3485.115389

Scherer, R., Howard, S., Tondeur, J., \& Siddiq, F. (2021). Profiling teachers' readiness for online teaching and learning in higher education: Who's ready? https://doi.org/10.1016/j.chb.2020.106675

Schleicher, A. (2020). Learning from international education responses to the crisis. Paper presented at Online meeting of the OECD Global Parliamentary Network. Retrieved from https://www.oecd.org/parliamentarians/meetings/gpn-meeting-october-2020/ 
Too old to teach? Experiences of online teaching among FCS instructors aged 50 years old and up

Sorebo, O., Halvari, H., Gulli, V., \& Kristiansen, R. (2009). The role of self-determination theory in explaining teachers. https://doi.org/10.1016/j.compedu.2009.06.001

urwanto, A., Asbari, M., Fahlevi, M., Mufid, A., Agistiawati, E., Cahyono, Y., \& Suryani, P. (2020) Impact of work from home on Indonesian teachers' performance during the COVID-19 pandemic: An exploratory study. International Journal of Advanced Science and Technology, 29(5), 6235 - 6244.

Wilichowski, T., \& Cobo, C. (2020). From coping to improving and accelerating: Supporting teachers in the pandemic and beyond. Retrieved from

https://blogs.worldbank.org/education/coping-improving-and-accelerating-supporting-teachers-pandemi c-and-beyond

Yurcaba, J. (2020). How teachers are coping with the new realities of the COVID-19 classroom. Retrieved from https://www.verywellmind.com/teaching-struggles-during-covid19-5087307

Zhao, Y., Guo, Y., Xiao, Y., Zhu, R., Sun, W., Huang, W., Liang, D., Tang, L., Zhang, F., Zhu, D., \& Wu, J. L. (2020). The effects of online homeschooling on children, parents, and teachers of grades 1-9 during the COVID-19 pandemic. Medical Science Monitor: International Medical Journal of Experimental and Clinical Research, 26, e925591. https://doi.org/10.12659/MSM.925591 
Balce, S. E.

22 Consortia Academia Publishing (A partner of Network of Professional Researchers and Educators) 